\title{
MATHEFUNIC: A MOBILE BASED GAME FOR ENGAGING CHILDREN WITH ADHD
}

\author{
Ibrahim Said Ahmad, Hafsa Kabir Ahmad, Saminu Muhammad Aliyu, Ahmad Muhammad Ahmad \\ Faculty of Computer Science and Information Technology, Bayero University Kano, Nigeria \\ isahmad.it@buk.edu.ng, hkahmad.cs@buk.edu.ng, smaliyu.cs@buk.edu.ng, amahmad.it@gmail.com
}

\begin{abstract}
Attention Deficit Hyperactivity Disorder (ADHD) is a common neurobehavioral disorder that is prevalent in children and adolescents. ADHD affects student's learning due to its symptoms which are inability to stay focused, hyperactivity, and challenges in self-control. In this paper, we explore the use of mobile games to engage children diagnosed with ADHD. Mobile games are now widely used in learning, which is part of mobile learning. Previous studies have shown a positive relationship between digital games and learning for children with ADHD. Therefore, we designed and developed a mobile game based on existing literature on techniques used to retain the attention and engage children with ADHD. The study was evaluated based on the duration of time the children spent playing the game and their activities and interactions while playing the game. Our findings showed that mobile-based games can be used to engage children with ADHD.
\end{abstract}

Keywords—ADHD, Behavioural Disorder, Mobile Learning, Smartphone, Mobile Devices.

\section{INTRODUCTION}

The advances in Information Technology (IT) over the years have led to the development of mobile phones, PDAs, and now the popular smartphones and tablets, all referred to as mobile devices [1], [2]. Mobile Devices are becoming more common, user-friendly and still very powerful. Modern Mobile devices are usable for children from early ages to elderly people as long as they can read and move. Children and young adults are now mostly occupied by using these mobile devices for playing games or any of the stocked applications available [3]. Consequently, the use of mobile technologies is of paramount importance in education. The use of mobile devices in learning process referred to as mobile learning (m-learning). In this paper, we explore the use of m-learning through mobile games to engage children with Attention Deficit Hyperactivity Disorder (ADHD). This is important considering the simplicity, and ease of access to mobile devices. The study is vital as it can provide an alternative means of teaching children with ADHD. Bul et al., [4] showed that children with ADHD are less distracted when playing digital games than when doing other activities and therefore using these digital games like mobile games have the potential to be used for engaging children with $A D H D$ in a learning process.

ADHD is a commonly diagnosed neurobehavioral disorder that affects a substantial number of children and adolescent (less than 18 years of age). Children with ADHD find it difficult to stay focused, are hyperactive, and might not perform well in school. About $5.29 \%$ and $7.1 \%$ of the world population is affected by this disorder [5]. Children with ADHD can be grouped based on symptoms with one group showing inattention only, another hyperactivity or impulsiveness and then a group which evidences all the symptoms [6]. Several studies have been reported in literature on the relationship between computer technologies and learning process of children with ADHD, including improving the learning and skill acquisition of individuals with special needs [7], improving ADHD individuals' executive functions through [6], and engaging children with ADHD using Sifteo cubes technology [8].

Despite the number of useful studies reported in the literature, there are limited studies on engaging children with ADHD using mobile games. Therefore, the key objectives of this research are:

1. To determine the methods used in retaining the attention and engaging children with ADHD that can be incorporated into a mobile game.

2. To design and develop a mobile game for retaining the attention and engaging children with ADHD.

3. To determine the effectiveness of mobile games in retaining the attention of children with ADHD.

The remainder of this paper is organized as follows: the literature review is presented in Section 2, while Section 3 discusses the research methodology. The results and discussion are presented in Section 4. Finally, the conclusion is presented in Section 5 . 


\section{LiTERATURE REVIEW}

\section{A. Categories of Mobile Technology}

Mobile technology is a term that is generally used to refer to such technologies that are mobile and portable. Mobile technologies are escalating transformations of technologymediated teaching and learning pedagogy [9]. The rapid advances in mobile technologies provide great potential that can facilitate people to be able to work in a dynamic mobile environment [10]. According to [11] mobile technologies can be defined as technologies that are mobile and personal like a mobile phone. They classified mobile technologies into personal static, shared and portable technologies as shown in Figure 1. The diagram below shows the classification of mobile technologies. The classification consists of a Cartesian plane with each of the categories on each axis. The mobile devices are placed in a quadrant depending on the properties of such device [11].

The first quadrant consists of mobile devices that are considered as personal and portable. It means such technologies that provide personal interactions with the user and which can be carried along everywhere. Mobile phones, PDA's, Laptops are seen to fall under this category because they are personal as they are owned by one person and they can be carried along all the time.

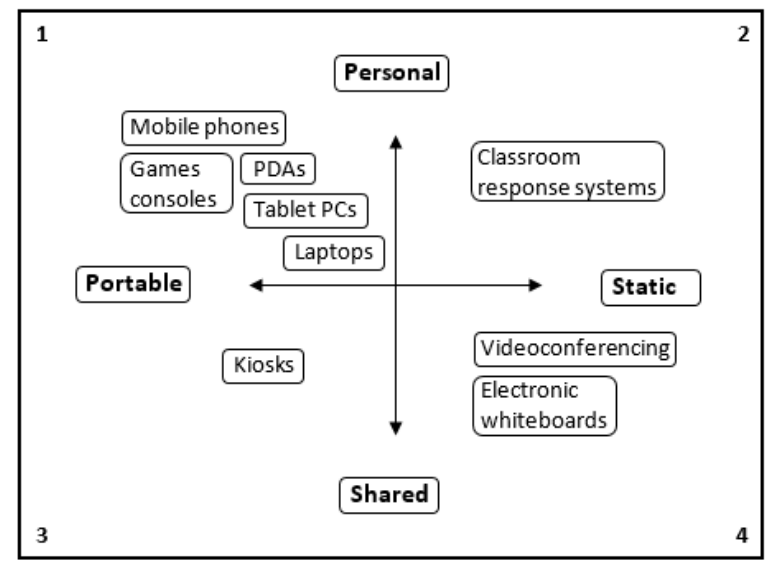

Fig. 1 Classification of Mobile Technologies [11].

The second quadrant includes such technologies that cannot be moved from one place to another, non - portable devices but still provides personal interactions with the users. The classroom response system is a technology that provides one to one interaction between teachers and students and enables students to answer multiple-choice questions. They are static because they cannot be moved out of the classroom but are still small enough to be considered as personal and are commonly assigned to a single student.

The third quadrant consists of technologies that are portable and also shared. Being able to be moved physically from one place to another is not the only definition of portability when it comes to mobile technologies. Street kiosks, interactive museum displays, etc. provides a form of ubiquitous interactions with people but these devices are not physically portable. It is the users that are portable but not the devices. These technologies are large which makes them less personal and so they are considered as shared because they are normally shared among many people.

The fourth quadrant can represent technologies that are shared and static. These devices are barely portable but they include it to show a complete space of possibilities of their classification [12].

\section{B. Mobile Learning}

Mobile Learning came into being in the late 1990s [13]. Mobile Learning refers to a form of learning that focuses on portable mobile devices like PDAs, tablets, smartphones for learning purposes [1]. Mobile learning can be seen as electronic learning delivered through portable mobile devices. Electronic learning refers to the learning process that utilizes electronic medium specifically Information and communication technologies to facilitate learning [14]. Mobile learning is essential and of vital importance because of its mobility and ease of access. Learning can take place virtually anytime anyplace.

The use of mobile technologies is changing the way we learn, learning can now effectively take place on the go anytime anywhere. According to [15], the effective use of mobile technology for learning will facilitate equality in learning opportunities for students by removing the time zone and distance barrier. The mobile devices are quite small and portable enough to allow learners use these devices anytime and anywhere to interact with different learners across the globe and discuss or share ideas depending on their various specializations and can even work collaboratively to finish some assigned task.

According to [3], there are four fundamental elements in any mobile learning platform. They are the learners, instructors, teaching contents and teaching method. They further point out the features of mobile learning as compared to traditional learning which are mobility, realtime, interactive, virtualization, digitization and individuation. In a different research, [16] argued that the characteristics of mobile learning are accessibility, immediacy, interactivity, permanency, and flexibility. These indicate that generally, every mobile learning platform should be at least ubiquitous, flexible and reliable in realtime.

A detailed classification of mobile learning technologies was by [12]. They argued that the existing classifications support the information itself and the method used to access the information. And so, the existing classifications don't include some vital systems that don't correspond to their progress. They further pointed out that these existing 
classifications don't account for the complexity of modern mobile learning systems and the support for e-learning standards and specifications.

Figure 2 shows their classification of Mobile Learning systems which is basically into Mobile devices, communication technology, information, location and communication mode between teachers and students.

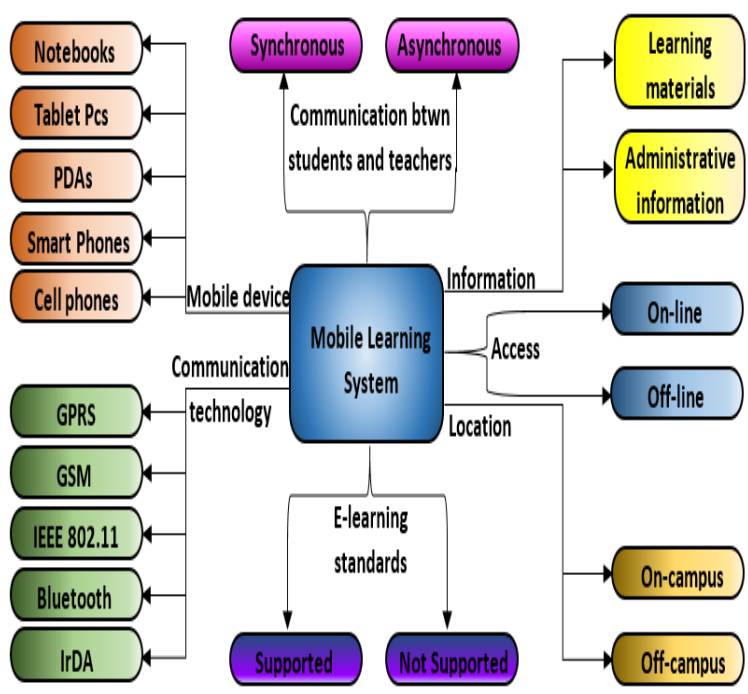

Fig. 2 A general classification of m-learning systems [12]

With the advent of mobile learning, which is a new learning style, it becomes imperative to have some guiding strategies and theories that will guide this pristine mode of learning for effectiveness and efficiency and to achieve all possibilities that the learning style can provide. This will ensure some uniformity and a form of standard. According to [17], taking mobile learning from other forms of learning perspectives like teaching theory, communication theory, and design theory can facilitate the understanding of this new learning style. Mobile learning is closely related to several learning theories. [17] used ordinary and familiar concept of learning as a based that will facilitate the understanding of mobile learning in education. Their research showed that according to characteristics of learners, learning styles of learners, a variety of mobile learning device, and learning resources mobile learning can be broadly classified into four main categories as listed below:

1. The regularity of Forgetting based Refresher Learning.

2. Pleasant Education based Game Learning.

3. Discussion-based Cooperative Learning.

4. Some Common Mistakes.

\section{Mobile Game-Based Learning ( $\mathrm{mGBL}$ )}

Mobile Game-Based Learning ( $\mathrm{mGBL}$ ) is a term used to refer to games that are specifically designed for mobile devices like smartphones and PDA's in which their primary target is learning. The aim of mobile game-based learning is to use the gameplay to enhance the motivation for learning [18]. According to [19] game-based learning has been proven to be a kind of learning method that enables students learning new things through gameplay thereby elevating motivation for learning.

The rapid advances and development in mobile technologies have made learning to become independent of specific time or location. They provide a wide range of possibilities to revolutionize teaching and learning now. Combining mobile learning and mobile game-based learning can bring about this revolution in education [20].

Games are known as a successful medium which propels individuals to play, collaborate, impart and learn. Game and learning could be effectively created and executed in the learning environment by combining both game design and instructional design approaches and by considering different issues, for example, learning theories, the theory of play, game design, and instructional design [18].

\section{Engaging Children with ADHD}

Children with ADHD seek attention by speaking out of turn, moving around and distraction others. They find it difficult to follow instructions and they have problem with completing long tasks. To be able to effectively impart knowledge to anybody, there is a need to get his attention and this makes the study of how to engage children with ADHD vital to this research. Existing research showed that the use of multimedia and hypermedia contents while teaching children with ADHD can help in retaining their attention. Multimedia contents include sounds, images, and graphs while hypermedia is an extension of multimedia and can consist of graphics, audio, video, plain text and hyperlinks. Hypermedia has the advantage of providing learners with the ability and flexibility to decide which content to view first and so they have some control over the instructional medium [21].

Reward system is also an important factor to consider while teaching children with Attention Hyperactivity Disorder. Children with ADHD are more sensitive to rewards [22]. Providing some form of reward for every successful accomplishment can greatly help in engaging them during the learning process. [23] emphasis on the use of reward in engaging and controlling the behaviour of children with ADHD. They proposed many ways that reward can be used in controlling the behaviour of children with ADHD and how it can be used in engaging them. They pointed out that rewards should be awarded frequently and should be withheld for uncompleted tasks or failing to follow instructions [24].

\section{E. Electronic Learning for Children with ADHD}

There is no cure for Attention Deficit Hyperactivity Disorder, even though treatment for the core symptoms is 
available. This treatment has a lot of side effect like migraine, vomiting, etc. and it is quite worrying for parents to see their children taking strong antibiotics. There is a need for an alternative and more efficient way to manage ADHD [21]. Several studies have been conducted on electronic learning for children with Attention Deficit Hyperactivity Disorder. [24] proposed an innovative alternative approach to ADHD therapy. It consists of a digital game that they hope to improve children with ADHD attention effectively while playing the game. The game consists of two sets which each consisting of four games. They used the principle of activity design with the concept of game theory in behaviour therapy and cognitive behaviour therapy to develop the game. This game is however designed for personal computers [24].

\section{F. Effect of Games on Children with ADHD}

[8] investigate the potentials of engaging children with ADHD using Sifteo cubes technology. They reported positive results that showed that the attention of children with ADHD can be retained using the Sifteo cubes technology. [19] explored the incorporation of breathing exercise in game design to develop a game called ChillFish. The purpose is to help children with ADHD to attain a relaxed state. Their findings showed that playing with the game helps the participants attain a relaxed state. [5] developed an iPadBased tool to help improve improving the skills of children with ADHD, specifically their reading skills. The experimental results obtained showed a positive result. Similarly, [4] developed a game called Plan-It Commander to improve the behavioural learning of children with ADHD. Strategies for day-to-day activities were explored for example time management and self-organization. The results of a usability study revealed a positive acceptance of the game by children with ADHD and their parents.

\section{ReseARCh Methodology}

\section{A. Instrument Development and Data Collection}

The data collection was carried out using a qualitative method, namely semi-structured observation. First, as no existing mobile game was found to incorporate significant elements used in engaging children with ADHD, a new mobile game was developed. The mobile game was developed for Android smartphones. The development technologies used for the development are Java, XML, SQLite, and Eclipse ADT. Secondly, children with ADHD were introduced to the game and were allowed to freely play the game while their actions and activities were recorded using an observation table shown in Table 1. The Observations were grouped into four main aspects each of which has some attributes, and the attributes are classified as either positive or negative. The four main aspects are body language, facial expressions, in-game behaviour and comments.

TABLE I

OBSERVATION TABLE

\begin{tabular}{|c|c|c|}
\hline $\begin{array}{l}\text { Type of } \\
\text { Observation }\end{array}$ & $\begin{array}{l}\text { Positive / } \\
\text { Negative }\end{array}$ & Actions Observed \\
\hline \multirow[t]{2}{*}{$\begin{array}{l}\text { Facial } \\
\text { Expression }\end{array}$} & Positive & $\begin{array}{l}\text { Concentrating/ attentive } \\
\text { Concerned } \\
\text { Surprised / shocked }\end{array}$ \\
\hline & Negative & $\begin{array}{l}\text { Bored } \\
\text { Distracted }\end{array}$ \\
\hline \multirow[t]{2}{*}{$\begin{array}{l}\text { Body } \\
\text { Language }\end{array}$} & Positive & $\begin{array}{l}\text { Focusing on screen } \\
\text { Leaning towards screen } \\
\text { Settled }\end{array}$ \\
\hline & Negative & $\begin{array}{l}\text { Fidgeting } \\
\text { Looking around the room }\end{array}$ \\
\hline \multirow[t]{2}{*}{ Comments } & Positive & $\begin{array}{l}\text { Discussion of game } \\
\text { elements } \\
\text { Laughs } \\
\text { Assertion of joy }\end{array}$ \\
\hline & Negative & $\begin{array}{l}\text { Assertion of boredom } \\
\text { Discussion of issues outside } \\
\text { of the game } \\
\text { Requests to stop the } \\
\text { activity }\end{array}$ \\
\hline \multirow[t]{2}{*}{$\begin{array}{l}\text { In-game } \\
\text { Behaviour }\end{array}$} & Positive & $\begin{array}{l}\text { Staying on task } \\
\text { Following instructions }\end{array}$ \\
\hline & Negative & $\begin{array}{l}\text { Spending a long time on a } \\
\text { question } \\
\text { Answering questions } \\
\text { randomly } \\
\text { Skipping tasks } \\
\text { Ignoring tasks }\end{array}$ \\
\hline
\end{tabular}

B. Mathefunic

A mobile game called Mathefunic was developed based on literature review, focusing on implementing features that can help in retaining the attention of the subjects. The game was developed for an Android operating system using native application development methods and toolkit. Figure 3 contains screenshots from the mobile game.
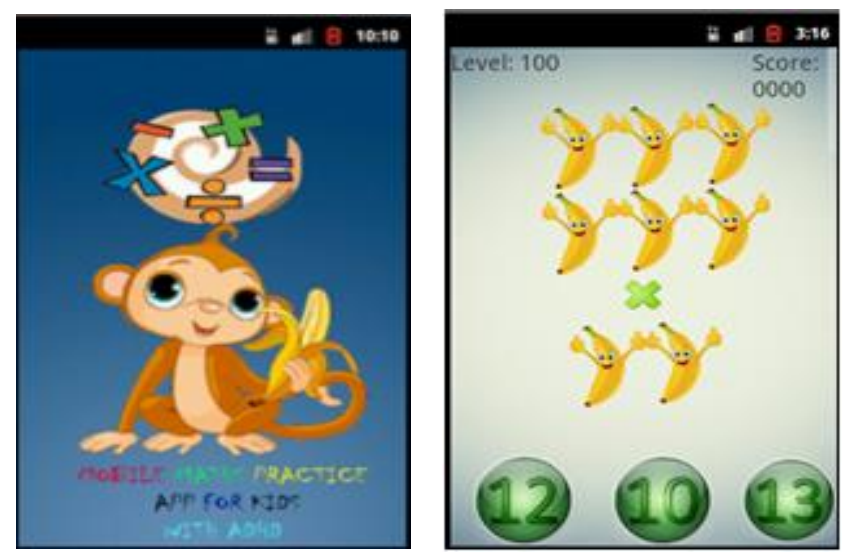

Fig.3 Screenshots from Mathefunic 


\section{Usability Testing}

Usability testing is used to verify the usefulness and efficiency of a new system. Mobile application usability testing is specifically very important because of the wide range of devices available and the several interactions possible with these mobile devices. We conducted usability testing on two major constructs: Effectiveness and Userfriendliness/Ease of Use constructs. These tests were conducted to verify the effectiveness, ease of use and friendliness of the user interface design of the mobile game. A usability questionnaire was used to get feedback from the participants during the testing. The participants followed the actions listed in a prepared task list. After performing the tasks, the participants filled up the questionnaire based on their experience from the test. This testing aims to ensure that all the features included work as intended on several Android smartphones, the buttons and options are clear enough and readable and to ensure children with ADHD can use the mobile game with no or minimal instructions.

\section{RESULTS AND DISCUSSION}

\section{A. Results of Usability Testing}

The result of usability testing is presented in Table 2. Questions marked with * are negatively worded questions. The questions are on a standard 5-point Likert scale [25]. The points are strongly disagree (1), disagree (2), neither agree nor disagree (3), agree (4), and strongly agree (5). Question one and two are for effectiveness construct, while questions three to ten are for User-friendliness and Ease of Use construct. The average ratings for the first and second questions are 3.6 and 3.8 respectively. The high rating in effectiveness construct shows that on average, the participants are impressed with the mobile game and agree that the mobile game is interactive and able to get and retain the attention of children with ADHD. This has shown that the mobile game is effective in fulfilling its designed goal.

Questions six, seven, and ten are negatively worded questions and have low averages of $0.8,0.6$, and 0.6 respectively. On the other hand, the remainder of the questions are positively worded and have high averages of $4.0,4.2,4.3,4.1$, and 5.0 respectively. The values mean that the participants are satisfied with how easy it is to start the game, navigate through it and play the game. In general, the usability testing result shows that the mobile game is acceptable, and the functions and objectives are clear enough for the research to be conducted.

The result of usability testing is presented in Table 2. Questions marked with * are negatively worded questions. The questions are on a standard 5-point Likert scale [25]. The points are strongly disagree (1), disagree (2), neither agree nor disagree (3), agree (4), and strongly agree (5). Question one and two are for effectiveness construct, while questions three to ten are for User-friendliness and Ease of Use construct. The average ratings for the first and second questions are 3.6 and 3.8 respectively. The high rating in effectiveness construct shows that on average, the participants are impressed with the mobile game and agree that the mobile game is interactive and able to get and retain the attention of children with ADHD. This has shown that the mobile game is effective in fulfilling its designed goal.

Questions six, seven, and ten are negatively worded questions and have low averages of $0.8,0.6$, and 0.6 respectively. On the other hand, the remainder of the questions are positively worded and have high averages of $4.0,4.2,4.3,4.1$, and 5.0 respectively. The values mean that the participants are satisfied with how easy it is to start the game, navigate through it and play the game. In general, the usability testing result shows that the mobile game is acceptable, and the functions and objectives are clear enough for the research to be conducted.

TABLE II

RESULT OF USABILITY TESTINC

\begin{tabular}{|c|c|c|}
\hline No & Question & $\begin{array}{l}\text { Average } \\
\text { Rating }\end{array}$ \\
\hline 1 & $\begin{array}{l}\text { The mobile game can effectively get and } \\
\text { retain the attention of players based on } \\
\text { your understanding of attention and } \\
\text { concentration }\end{array}$ & 3.6 \\
\hline 2 & $\begin{array}{l}\text { The mobile game is interactive and can } \\
\text { be played for several hours without } \\
\text { getting bored or distracted. }\end{array}$ & 3.8 \\
\hline 3 & $\begin{array}{l}\text { The game design and layout are properly } \\
\text { done, and all the contents can be easily } \\
\text { identified }\end{array}$ & 4.0 \\
\hline 4 & $\begin{array}{l}\text { There is no need for any guide to be able } \\
\text { to play and explore all the options in the } \\
\text { mobile game }\end{array}$ & 4.2 \\
\hline 5 & $\begin{array}{l}\text { The texts, colours used, and images are } \\
\text { clear and nicely selected. }\end{array}$ & 4.3 \\
\hline 6 & $\begin{array}{l}\text { Some of the functions in the mobile } \\
\text { game are not fully clear. }\end{array}$ & 0.8 \\
\hline 7 & $\begin{array}{l}\text { Some of the contents of the mobile } \\
\text { game does not match with their intent. }\end{array}$ & 0.6 \\
\hline 8 & $\begin{array}{l}\text { It is very easy to start the game and } \\
\text { create a new player }\end{array}$ & 5.0 \\
\hline 9 & $\begin{array}{l}\text { It is very easy to swap and navigate } \\
\text { between the menus in the game. }\end{array}$ & 4.1 \\
\hline 10 & $\begin{array}{l}\text { Players can get stuck while trying to } \\
\text { perform an action in the mobile game }\end{array}$ & 0.6 \\
\hline
\end{tabular}

\section{B. Results of Observation}

Figures 4 through 7 shows the analysis of the observation data recorded. From the observation, all the participants played the mobile game developed for averagely 20 minutes voluntarily. Figure 4 shows the body language of the participant while playing the game. The average time the 
participants were focused on the screen is $60 \%$. This indicates that the participants were engaged with playing the game. Also, Figure 5 shows that the participants stayed on task with average $50 \%$ but $35 \%$ for following the instruction which is in agreement with existing literature on children with ADHD that they find it difficult to follow instructions. Figures 6 and 7 all indicate a high level of engagement of the participants with the game. Based on the ethnographic studies and analysis of the interview, it can be concluded that that mobile games can help in enhancing the level of concentration and attention of children with ADHD and thereby aid their learning progress.

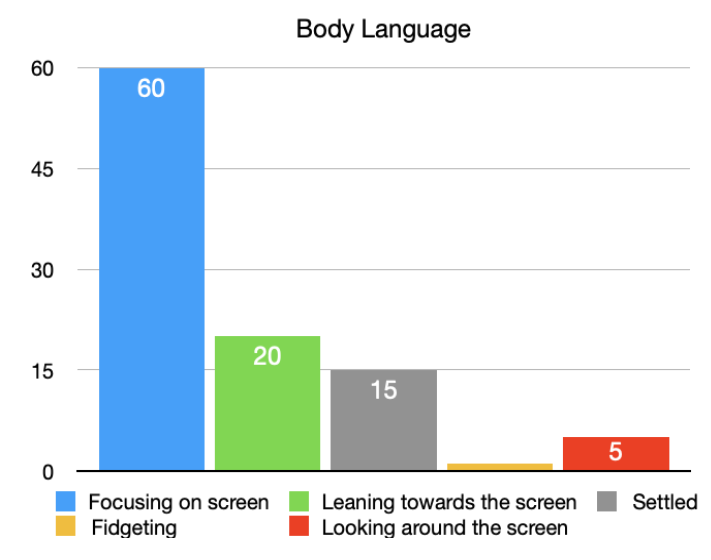

Fig. 4 Body Language results

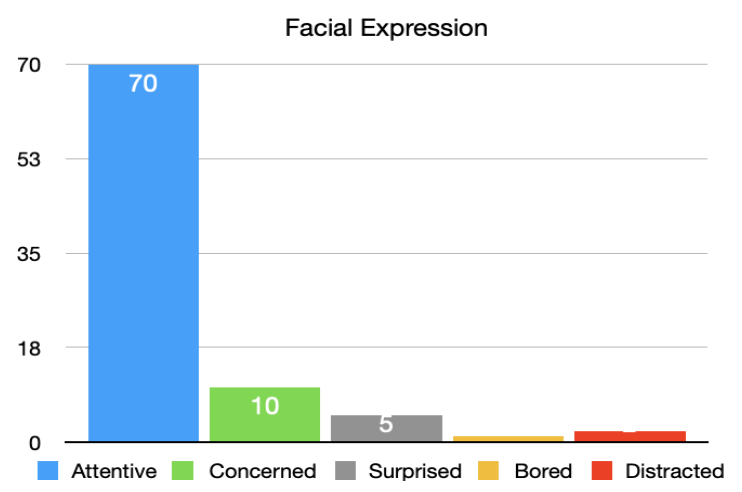

Fig. 5 Facial Expression results

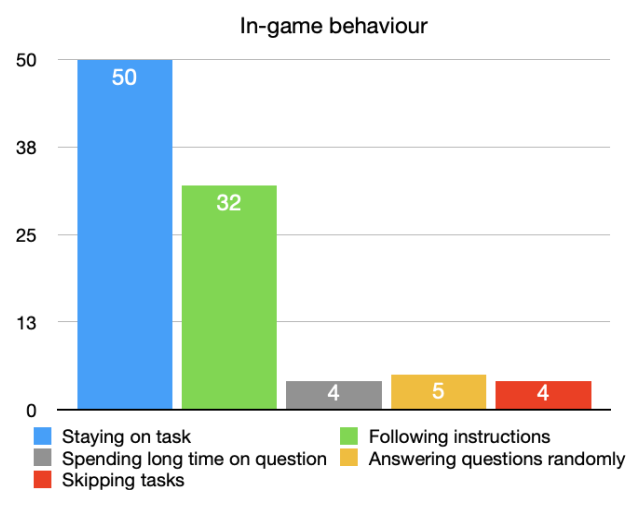

Fig.6 In-game behaviour results

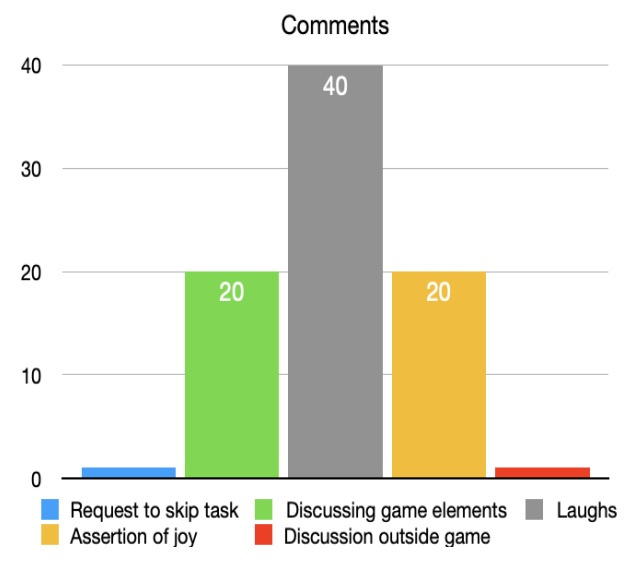

Fig. 7 Comments results

\section{CONCLUSION}

In this paper, we investigated the effectiveness of mobile games in engaging children with ADHD for educational purposes. An android mobile game was developed to include features used in retaining the attention of a child with ADHD. Based on analysis of the ethnographic studies and the video captured, and also comparing the results with literature about the average duration children with ADHD can concentrate on any particular tasks, the result indicates a much higher percentage of interest in the game. This suggests that mobile games can help in enhancing the level of attention and concentration of students with ADHD and can thereby aid their learning process. The mobile game developed was based on literature studied on learning strategies and learning theories for children with ADHD, and the results of the testing suggest that using high-quality multimedia contents, a regular and frequent reward for success, short sounds clips, simple graphics and short tasks in mobile games can assist in engaging students with ADHD.

\section{REFERENCES}

[1] M. V. García, M. F. Blasco López, and M. Á. Sastre Castillo, "Determinants of the acceptance of mobile learning as an element of human capital training in organisations," Technol. Forecast. Soc. Change, vol. 149, p. 119783, Dec. 2019, doi: 10.1016/j.techfore.119783. 2019

[2] U. Cahyana, H. A. Yuanita Marwa, Erdawati, M. Paristiowati, and Y. Rahmawati, “Mobile Learning to Development of Students' Selfconcept of Chemistry," Univers. J. Educ. Res., vol. 7, no. 12 A, pp. 93100, Dec. 2019, doi: 10.13189/ujer.071912. 2019

[3] I. García-Martínez, J. M. Fernández-Batanero, D. Cobos Sanchiz, and A. Luque de la Rosa, "Using Mobile Devices for Improving Learning Outcomes and Teachers' Professionalization," Sustainability, vol. 11, no. 24, p. 6917, Dec., doi: 10.3390/su11246917. 2019

[4] K. C. M. Bul et al., "Development and User Satisfaction of 'Plan-It Commander,' a Serious Game for Children with ADHD," Games Health J., vol. 4, no. 6, pp. 502-512, Dec. 2015, doi: 10.1089/g4h.0021.2015

[5] N. Wrońska, B. Garcia-Zapirain, A. Mendez-Zorrilla, N. Wrońska, B. Garcia-Zapirain, and A. Mendez-Zorrilla, "An iPad-Based Tool for Improving the Skills of Children with Attention Deficit Disorder," Int. J. Environ. Res. Public Health, vol. 12, no. 6, pp. 6261-6280, Jun., doi: 
10.3390/ijerph120606261. 2015

[6] E. Alabdulakareem and M. Jamjoom, "Computer-assisted learning for improving ADHD individuals' executive functions through gamified interventions: A review," Entertain. Comput., vol. 33, Mar, doi: 10.1016/j.entcom.2020.100341. 2020

[7] R. S. Baragash, H. Al-Samarraie, A. I. Alzahrani, and O. Alfarraj, "Augmented reality in special education: a meta-analysis of singlesubject design studies,” Eur. J. Spec. Needs Educ., pp. 1-16, , doi: 10.1080/08856257.2019.1703548. 2019

[8] I. S. Ahmad, S. M. Aliyu, and H. K. Ahmad, "Towards the engagement of children with ADHD using Sifteo cube technology," Asia-Pacific J. Inf. Technol. Multimed., vol. 8, no. 2, pp. 19-29, Dec, doi: 10.17576/apjitm-2019-0802-02 . 2019

[9] S. Chin, "Mobile technology and Gamification: The future is now!," in 2014 4th International Conference on Digital Information and Communication Technology and Its Applications, DICTAP 2014, 2014, pp. 138-143, doi: 10.1109/DICTAP.6821671.2014

[10] S. Vongjaturapat and C. Singha, "Mobile technology acceptance for library information service: A theoretical model," in International Conference on Information Society (i-Society 2013), , pp. 290-292, Accessed: Apr. 11, 2020. [Online]. Available: https://ieeexplore.ieee.org/abstract/document/6636393/.2013

[11] L. Naismith, P. Lonsdale, G. N. Vavoula, and M. Sharples, Literature review in mobile technologies and learning a report for NESTA Futurelab. NESTA Futurelab, 2004.

[12] E. Georgieva, S. Angel, and G. Tsvetozar, "A general classification of mobile learning systems," in International Conference on Computer Systems and Technologies-CompSysTech, , pp. 6-14, [Online]. Available:https://www.researchgate.netprofile/Tsvet ozar Georgiev2/publication/301673819 A General Classification of _Mobile_Learning_Systems/links/5720c34208aedo56fa29ofa8.pdf. 2005

[13] N. F. Taharim, A. Mohd Lokman, W. A. R. Wan Mohd Isa, and N. L. Md Noor, "A relationship model of playful interaction, interaction design, kansei engineering and mobile usability in mobile learning," in 2013 IEEE Conference on Open Systems, ICOS 2013, 2013, pp. 22-26, doi: 10.1109/ICOS.6735041. 2013

[14] F. Mikic, L. Anido, E. Valero, and J. Picos, "Accessibility and mobile learning standardization," in Second International Conference on Systems (ICONS'07), p. 32, [Online]. Available: https://ieeexplore.ieee.org/abstract/document/4196334/.2007
[15] M. Ally and P.-B. Josep, "What is the future of mobile learning in education?," Int. J. Educ. Technol. High. Educ., vol. 11, no. 1, pp. 142-151, doi: 10.7238/rusc.v11i1.2033. 2014

[16] S. K. Behera, "M-learning: A new learning paradigm," Int. J. New Trends Educ. Their Implic., vol. 4, no. 2, pp. 24-32, [Online]. Available: http://www.ijonte.org/FileUpload/ks63207/File/2013.2. complete.pdf\#page $=31.2013$

[17] J. Yuan, R. Xing, and J. Wang, “Applying research of mobile learning mode in teaching," in Proceedings - 2010 International Forum on Information Technology and Applications, IFITA 2010, 2010, vol. 3, pp. 417-420, doi: 10.1109/IFITA.352. 2010

[18] N. Shiratuddin and S. B. Zaibon, "Designing user experience for mobile game-based learning," in Proceedings - 2011 International Conference on User Science and Engineering, i-USEr 2011. pp. 89-94, doi: 10.1109/iUSEr.2011.6150543. 2011

[19] T. Sonne and M. M. Jensen, "ChillFish: A respiration game for children with ADHD," in TEI 2016 - Proceedings of the 10th Anniversary Conference on Tangible Embedded and Embodied Interaction, Feb, pp. 271-278, doi: 10.1145/2839462.2839480. 2016

[20] A. Bartel and G. Hagel, "Engaging students with a mobile game-based learning system in university education," in IEEE Global Engineering Education Conference, EDUCON, 2014, pp. 957-960, doi: 10.1109/EDUCON.6826215. 2014

[21] R. A. Fabio and A. Antonietti, "Effects of hypermedia instruction on declarative, conditional and procedural knowledge in ADHD students," Res. Dev. Disabil., vol. 33, no. 6, pp. 2028-2039, Nov. 2012, doi: 10.1016/j.ridd.2012.04.018.

[22] G. Tripp and B. Alsop, "Sensitivity to Reward Delay in Children with Attention Deficit Hyperactivity Disorder (ADHD)," J. Child Psychol. Psychiatry, vol. 42, no. 5, pp. 691-698, Jul. doi: 10.1111/14697610.00764. 2001,

[23] A. Miranda, S. Jarque, and R. Tarraga, "Interventions in School Settings for Students With ADHD," Exceptionality, vol. 14, no. 1, pp. 35-52, Jan, doi: 10.1207/s15327035ex14014. 2006

[24] T.-Y. Chuang, I.-C. Lee, and W.-C. Chen, "Use of digital console game for children with attention deficit hyperactivity disorder," US-China Educ. Rev., vol. 7, no. 11, pp. 99-105, Accessed: Apr. 11, 2020. [Online]. Available: http://www.uho.com.tw/sick.asp?aid=4500. 2010

[25] S. O. Leung, "A comparison of psychometric properties and normality in 4-, 5-, 6-, and 11-point likert scales," J. Soc. Serv. Res., vol. 37, no. 4, pp. 412-421, Jul., doi: 10.1080/01488376.2011.58069 7. 2011 